\title{
Importance of the number emission factor of combustion-generated aerosols from nano-enabled products
}

\author{
Tobias Hammer $^{\mathrm{a}, \mathrm{b}}$, Nathan Bossa ${ }^{\mathrm{c}}$, Michael Persson ${ }^{\mathrm{d}}$, Adrian Wichser ${ }^{\mathrm{b}}$, Ken Lehner ${ }^{\mathrm{b}}$, \\ Emmanuel Ruggiero ${ }^{\mathrm{e}}$, Ana Sofia Fonseca ${ }^{\mathrm{f}}$, Milijana Jovic $^{\mathrm{g}}$, Sabyasachi Gaan ${ }^{\mathrm{g}}$, \\ Wendel Wohlleben ${ }^{\mathrm{e}}$, Jing Wang ${ }^{\mathrm{a}, \mathrm{b}, *}$ \\ ${ }^{a}$ Institute of Environmental Engineering, ETH Zürich, 8093 Zürich, Switzerland \\ ${ }^{\mathrm{b}}$ Laboratory of Advanced Analytical Technologies, Empa, 8600 Dübendorf, Switzerland \\ ${ }^{\mathrm{c}}$ Leitat Technological Center, 08225 Terrassa, Barcelona, Spain \\ ${ }^{\mathrm{d}}$ Nouryon PPC AB, 44580 Bohus, Sweden \\ ${ }^{\mathrm{e}}$ BASF SE, 67056 Ludwigshafen am Rhein, Germany \\ ${ }^{\mathrm{f}}$ National Research Centre for the Working Environment (NRCWE), Lerso Parkalle 105, DK-2100 Copenhagen, Denmark \\ ${ }^{g}$ Laboratory of Advanced Fibers, Empa, 9014 Sankt Gallen, Switzerland
}

\section{A R T I C L E I N F O}

\section{Keywords:}

Nanomaterial

Release of nanomaterials

Combustion

Categorization of nano-enabled products

\begin{abstract}
A B S T R A C T
Accidental or open waste burning and incineration of nano-enabled products (NEPs) might lead to the release of incidental aerosols in the nano size range into the environment resulting in harmful effects on humans.

We have investigated combustion-generated aerosol release during accidental burning for several real-life NEPs such as paints with silica $\left(\mathrm{SiO}_{2}\right)$ and spruce wood panels containing $\mathrm{SiO}_{2}$ and $\mathrm{Fe}_{2} \mathrm{O}_{3}$ nanomaterials (NMs), paper with $\mathrm{SiO}_{2}$ and $\mathrm{Fe}_{2} \mathrm{O}_{3} \mathrm{NMs}$ and polymeric composites with CuPhthtalocyanine NMs in poly lactic acid (PLA), polyamide 6 (PA6) and thermoplastic pol-urethane (TPU) matrices.

Chemical compositions, aerosols number emission factors $\left(\mathrm{n}_{\mathrm{efs}}\right)$ and concentrations of the signature elements of the NMs of the combustion-generated aerosols were investigated. In addition, the residual ash was analyzed. The outcomes of this study shed light on how NM and matrix types influenced the properties of the released aerosols. Based on our results it was established that the combustion-generated aerosols were composed of transformed NMs with modified physical-chemical characteristics compared to the pristine NMs. In addition to aerosols with transformed NMs, there were also particles due to incomplete combustion of the matrix.

Types of the pristine NMs and matrices affected the characteristics of the released aerosols. Since the effect of the aerosols is related to the inhaled aerosol number concentration, the $\mathrm{n}_{\mathrm{ef}}$ is an important parameter. Our results showed that the $\mathrm{n}_{\mathrm{efs}}$ in the size range of 5.6 to $560 \mathrm{~nm}$ depended strongly on the type of combusted NEP, which indicated that the NEPs could be categorized according to their potential to release aerosols in this size range when they were burnt. The generated release data facilitate the assessment of human and environmental exposure and the associated risk assessment of combustion-generated aerosols from NEPs.
\end{abstract}

\section{Introduction}

To take advantage of the extraordinary physical-chemical properties of nanomaterials (NMs), the amount of NMs used in consumer and industrial applications is continuously increasing (Breuer and Sundararaj, 2004, Nowack and Bucheli, 2007, Potts et al., 2011, Limited, 2011, Le et al., 2014, Singh et al., 2016, Gonçalves et al. 2018). Graphene nanoplatelets or carbon nanotubes show high electrical and thermal conductivity (Potts et al., 2011; Wang et al., 2017). NM pigments such as CuPhthalocyanine or $\mathrm{Fe}_{2} \mathrm{O}_{3}$ have extremely intense color due to their excellent light-scattering properties (Kotnarowska et al., 2014) and $\mathrm{SiO}_{2}$ nanoparticles have high mechanical stability (Mahrholz et al., 2009; Sow et al., 2011). To profit from these properties, NMs are applied in socalled nano-enabled products (NEPs) such as construction materials, paints, paper, cosmetics, sports products or in airplanes or automobiles (Kittelson et al., 2004; Nowack and Bucheli, 2007; Kuhlbusch et al.,

\footnotetext{
* Corresponding author at: Institute of Environmental Engineering, ETH Zürich, 8093 Zürich, Switzerland.

E-mail address: jing.wang@ifu.baug.ethz.ch (J. Wang).
} 
2010; Brar et al., 2010; Sow et al., 2011; Bello et al., 2013; Wang et al., 2017; Part et al., 2018; Surendhiran et al., 2020). According to Madkour, 2019, the global nanotechnology revenue is tremendously growing since about 1995.

Apart from the benefits, NMs or NEPs might also have adverse effects (Rothen-Rutishauser et al., 2006; Watson-Wright et al., 2017; Surendhiran et al., 2020). During the entire life cycle of a NEP, incidental and manufactured NMs can be released and human beings or the environment can be exposed and harmfully affected (Froggett et al., 2014; Seipenbusch et al., 2014; Nowack and Bucheli, 2007; Nowack et al., 2012; Roes et al., 2012). During the use phase, NM release can occur e.g. by material aging induced by weathering, or by mechanical treatment (abrasion, drilling, sawing, etc.). At the end of their life, NMs or NEPs are either directly disposed in a landfill or thermally decomposed in open waste burning or in waste incineration plants (Keller and Lazareva, 2014). Vejerano et al. (2014) found that 8600 tons of NMs were expected to be incinerated globally per year with increasing tendency. High temperatures and fragmentation and oxidation processes during the combustion lead to thermal decomposition of the NEPs and the release of incidental, process-generated nanoparticles in the form of fly ash into the air (Chivas-Joly et al., 2014; Wang et al., 2017; Singh et al., 2017; Singh et al., 2019; Hansen et al., 2015).

One of the most critical exposure routes for humans to such aerosols is the exposure pathway of inhalation, since the inhaled particles might deposit in the alveoli and the trachea bronchus of the respiratory system or can even penetrate into the blood (Rothen-Rutishauser et al., 2006). Once in the bloodstream the NMs are circulated in the whole body and could be transferred to vital organs such as brain or heart, where an agglomeration of the NMs can lead to severe diseases such as apoplexy or heart attacks (Rothen-Rutishauser et al., 2006; Pope III et al., 1995; Schulz et al., 2005). Toxicity and biological effects of the inhaled aerosols depend strongly on their concentration, as well as size, shape and chemical composition.

Since inhalation is the most probable exposure pathway to combustion-generated NMs (Basinas et al., 2018), and the combustiongenerated aerosol NMs might induce different adverse effects than the pristine NMs, aerosol concentrations and their physical-chemical properties need to be assessed (Roes et al., 2012). It is simplistic to take only the type of NM (organic, inorganic, chemical composition) into account for the risk assessment. Also other parameters such as the product matrix or the combustion parameters should be considered. The effect of the aerosols is directly related to the inhaled aerosol dose, which depends on the inhaled aerosol concentration (Hammer et al., 2020). The potential to release aerosols during the combustion could depend on the type of NEP burnt. Classification of the NEPs by similarity according to the aerosol release rate when they are burnt and readacross would save time and allow an effective risk assessment of the released aerosol NMs. Studies on aerosol release during accidental burning of real NEPs are still scarce and new and more data are needed to classify the NEPs.

Several studies (Wang et al., 2017; Chivas-Joly et al., 2019; Oischinger et al., 2019; Walser et al., 2012; Mitrano et al., 2015; Hansen et al., 2015) reported that the combustion-generated NMs show strongly transformed physical-chemical characteristics compared to the pristine NMs. Following the source-to-adverse-outcome pathway (SAOP) approach described by Oomen et al. (2015) and Landsiedel (2016), every modification of the physical-chemical properties of a NM needs to be taken into consideration for a risk assessment, since the physical-chemical properties of the generated NM define its final toxicity and its biological impact.

Combustion-induced NM release was studied previously for the incineration of municipal waste with $\mathrm{TiO}_{2}, \mathrm{ZnO}, \mathrm{Ag}$ and $\mathrm{CeO}_{2} \mathrm{NMs}$ (Mueller et al., 2013; Buha et al., 2014). Mueller et al. (2013) showed that the major fraction of the $\mathrm{NMs}\left(\mathrm{TiO}_{2}, \mathrm{ZnO}\right.$ and $\left.\mathrm{Ag}\right)$ went to the residual bottom ash and only a small fraction was released as fly ash. Buha et al. (2014) concluded that the operational conditions for the incineration (temperature, pressure, etc.) and the type of incinerated material (waste, NM) determined the chemical composition of the residual ash and the generated aerosol.

Singh et al. (2019) found that the operation conditions of the combustion affected the release of NMs. At a temperature of $500{ }^{\circ} \mathrm{C}$, inorganic NMs such as $\mathrm{CuO}, \mathrm{Fe}_{2} \mathrm{O}_{3}, \mathrm{SiO}_{2}$ stayed in the residual ash, whereas organic NMs e.g. DPP (diketopyrrolopyrrole) Red were decomposed and transformed into soot and $\mathrm{CO}_{2}$. At a temperature of $850{ }^{\circ} \mathrm{C}$ in incineration plants, the inorganic nanofillers remained mainly in the residual ash and only small concentrations of $\mathrm{Cu}$ and $\mathrm{Fe}$ signature elements of $\mathrm{CuO}$ and $\mathrm{Fe}_{2} \mathrm{O}_{3}$ were detected in the aerosols. Schlagenhauf et al. (2015), who incinerated epoxy composites with multi-walled carbon nanotubes (CNTs), showed that the oxygen content of the combustion air affected the final appearance, the total particle concentration and the chemical composition of the fly ash. Massari et al. (2014) found that $\mathrm{TiO}_{2}$ nanoparticles from solid paints were strongly physical-chemically modified and sintered with other ash residues and remained in the residual ash after the incineration using an incineration temperature of $950{ }^{\circ} \mathrm{C}$.

Release of so-called LCPM (life cycle particulate matter) that represents fly ash particles and residual ash has been investigated under labscale conditions for combusted polymer-based NEPs and nano-enabled coatings (NECs) with CNTs, $\mathrm{CuO}, \mathrm{Fe}_{2} \mathrm{O}_{3}, \mathrm{SiO}_{2}$ NMs (Sotiriou et al., 2015; Sotiriou et al., 2016; Singh et al., 2016; Singh et al., 2017; Singh et al., 2019). According to Singh et al. (2019), the higher the NM loadings in a NEP, the higher were the concentrations of the signature elements of the pristine NMs found in the fly ash. Moreover, the host matrix seemed to strongly affect the chemical composition of the LCPM (Sotiriou et al., 2016, Singh et al., 2016, Singh et al., 2017, Singh et al., 2019).

In this work, we investigated combustion-induced NM release during accidental / outdoor burning for several real-life NEPs such as applied paints containing $\mathrm{SiO}_{2}$ or $\mathrm{Fe}_{2} \mathrm{O}_{3} \mathrm{NMs}$ on spruce wood panels, paper with $\mathrm{SiO}_{2}$ and $\mathrm{Fe}_{2} \mathrm{O}_{3} \mathrm{NMs}$ and polymeric composites with $\mathrm{CuPh}$ thtalocyanine NMs in poly lactic acid (PLA), polyamide 6 (PA6) and thermoplastic polyurethane (TPU) matrices. During the experiment we followed the combustion protocol ISO 5660 ASTM E 1354. Accordingly, the combustion conditions included the oxygen concentration of ambient air $(20.95 \%)$ and a temperature of $570{ }^{\circ} \mathrm{C}$. With the aim to simulate particle release during accidental burning under outdoor conditions, this was intentionally different from the legally required conditions of waste incineration, where typically temperatures around $920^{\circ} \mathrm{C}$ are applied.

We compared the physical-chemical characteristics of the released particles and pristine NMs, to determine whether the pristine NMs were released in the fly ash. Moreover, the effects of types of matrices and NMs on the amount and the shape of the released aerosol were evaluated. By comparing aerosol number emission factors $\left(n_{e f s}\right)$, which were defined as the average emitted aerosol number per gram burnt NEP, we were able to assess the potential of the NEPs to release aerosols during combustion. Physical-chemical data and $n_{\text {efs }}$ facilitate the evaluation of the NM environmental release and workers' or consumers' exposure potential during the combustion of such materials and allow in combination with literature data a more comprehensive assessment of environmental health and safety.

\section{Materials and methods}

\subsection{Pristine nanomaterials and nano-enabled products}

Three different types of commercial NEPs were subjected to combustion: polymeric composites, wood panels with applied paints and paper. The NEPs contained NMs with high production volumes such as $\mathrm{Fe}_{2} \mathrm{O}_{3}$ (from BASF, Germany), $\mathrm{SiO}_{2}$ (from Nouryon, Sweden) and CuPhthalocyanine (from BASF, Germany) (Ministère de 1'Environnement, 2015; Ruggiero et al., 2019; Wigger et al., 2018). CuPhthalocyanine NMs present in different crystalline forms ( $\alpha$ and $\beta$ ) (from 
BASF, Germany) that had a (29H,31H-phthalocyaninato(2-)-N29,N30, N31,N32)copper(II) structure and a size of $14.6 \pm 4.9 \mathrm{~nm}$ were embedded in polymeric composites whereas different types of $\mathrm{Fe}_{2} \mathrm{O}_{3}$ and $\mathrm{SiO}_{2} \mathrm{NMs}$ were used in paints and papers. Silica silane $\left(\mathrm{SiO}_{2}\right)$ that was used with a loading of $6 \mathrm{wt} \%$ in the white paint (supplementary Table $\mathrm{S} 1 \mathrm{a})$ had a size of $12.05 \pm 2.3 \mathrm{~nm} . \mathrm{Fe}_{2} \mathrm{O}_{3}$ was used in different shapes (rods and spheres) and concentrations (1 and $7 \mathrm{wt} \%$ ) in the red paint samples the reddish paper. $\mathrm{Fe}_{2} \mathrm{O}_{3}$ (rods) and $\mathrm{Fe}_{2} \mathrm{O}_{3}$ (spheres) had a size of $8.4 \pm 1.8 \mathrm{~nm}$ and $36.7 \pm 12.4 \mathrm{~nm}$, respectively (supplementary Table $\mathrm{S} 1 \mathrm{a}, \mathrm{b})$. In addition, two types of silica $\left(\mathrm{SiO}_{2}\right.$ silica anis std. with a size of $14.0 \pm 6.64 \mathrm{~nm}$ and $\mathrm{SiO}_{2}$ silica anis $\mathrm{Al}$ with $13.08 \pm 2.3 \mathrm{~nm}$ ) were applied in the paper samples (supplementary Table S1a, b and c). More details may be referred to the supplementary Table S1.

\subsection{Setup of the combustion experiment and online particle detection}

We employed a Cone Calorimeter (Fire Testing Technology, FTT, GB) with a heat flux of $25 \mathrm{~kW} / \mathrm{m}^{2}$ resulting in a temperature of about $570{ }^{\circ} \mathrm{C}$ for the combustion and followed ISO 5660 ASTM E 1354 to simulate the burning of the NEPs that consisted of different matrix materials with various NM loadings (Table S1a-c). The oxygen concentration of the air was $20.95 \%$. The fuming samples were ignited through an electric spark, generated by an ignitor, at a distance of $0.3 \mathrm{~cm}$ without direct contact to the samples. A standardized sample surface area of $10 \mathrm{~cm} \times 10 \mathrm{~cm}$ was used. Polymeric composites samples had a thickness of $0.3 \mathrm{~cm}$ and wood panels with applied paint had a thickness of $1.5 \mathrm{~cm}$. Stacks of five paper sheets with a total thickness of $0.1 \mathrm{~cm}$ corresponded to one paper sample. The emitted aerosols were sampled through a circular inlet with a diameter of $5 \mathrm{~mm}$, diluted with filtered ambient air and transferred to the analytical instruments through a tubing system made of stainless steel.

Emitted aerosol size distributions (ASDs) in the size range of $5.6 \mathrm{~nm}$ to $560 \mathrm{~nm}$ were analyzed with $1 \mathrm{~Hz}$ frequency by using a fast mobility particle sizer (FMPS 3091, TSI). The ASDs in the size range of $542 \mathrm{~nm}$ to $20 \mu \mathrm{m}$ were scanned using an aerodynamic particle sizer (APS 3321, TSI) with scanning periods of $20 \mathrm{~s}$. Continuously, ASDs were recorded until the burning samples extinguished. The combustion experiments were repeated 3 times and the total aerosol concentrations of the FMPS and APS measurements were averaged per second. Prior to the experiment, when there was no combustion, background concentrations were measured for similar durations as for the respective samples, corresponding to about $150 \mathrm{~s}$ for paper samples, to $8 \mathrm{~min}$ for polymeric composite samples and to $17 \mathrm{~min}$ for wooden panels with applied paints. The background concentrations were subtracted from the aerosol concentrations from the experimental measurements with the samples.

The emitted fly ash was collected on Nuclepore filters with a pore size of $0.2 \mu \mathrm{m}$ (Whatman, UK) for offline analyses. Fig. 1 shows the experimental setup for the combustion tests.

\subsection{Determination of the aerosol number emission factors $\left(n_{e f s}\right)$}

The aerosol number emission factors $\left(n_{e f s}\right)$ correspond to the potential of a NEP to release aerosols during the combustion. The $n_{\text {efs }}$ were calculated for the FMPS size range of $5.6 \mathrm{~nm}$ to $560 \mathrm{~nm}$ and the APS size range of $542 \mathrm{~nm}$ to $20 \mu \mathrm{m}$ by using eq. (1). Potential particle losses in the tubes of the combustion setup was assumed to be similar for the different samples and neglected in the calculation.

$n_{e f}=\frac{c t}{m s} \times v i \times t \times d f \times c f$

with $c t$ averaged total concentration in the instrument range (FMPS or APS) in $\# / \mathrm{cm}^{3}$, $m s$ burnt sample mass in $\mathrm{g}$, vi volume flowrate to the instrument in $\mathrm{cm}^{3} / \mathrm{s}$ (FMPS: 166.6; APS: 16.6), $t$ duration of incineration in $s, d f$ dilution factor (FMPS: 1.4; APS: 14) equal to the total flowrate through the system divided by the flowrate of the instrument, cf correction factor (144 for FMPS and 1440 for APS) equal to the volume flowrate to the exhaust fan of the Cone Calorimeter (241/s) divided by the flowrate of the instrument (10 1/min for FMPS and $11 / \mathrm{min}$ for APS) to compensate the divergence of the flow rates and to estimate the total amount of released aerosols in the respective size ranges, since only a fraction of the released aerosols could be collected by the instrument.

\subsection{Qualitative determination of the morphology and the chemical composition of the fly ash and the residual ash}

Scanning electron microscope (SEM) was used to investigate the shape and the size of the released fly ash particles. For more details on the morphology evaluation, may be referred to the supplementary information. The chemical composition of the fly ash and the residual ash were scanned at several locations using electron dispersive X-ray-SEM (EDX-SEM, environmental scanning electron microscopy ESEM, Thermo Fisher Quanta 650) with a $10 \mathrm{kV}$ acceleration voltage. EDX analyses of the residual ash were done using SEM Phenom ProX (Phenom) with an acceleration voltage of $10 \mathrm{kV}$. The measured values were averaged over

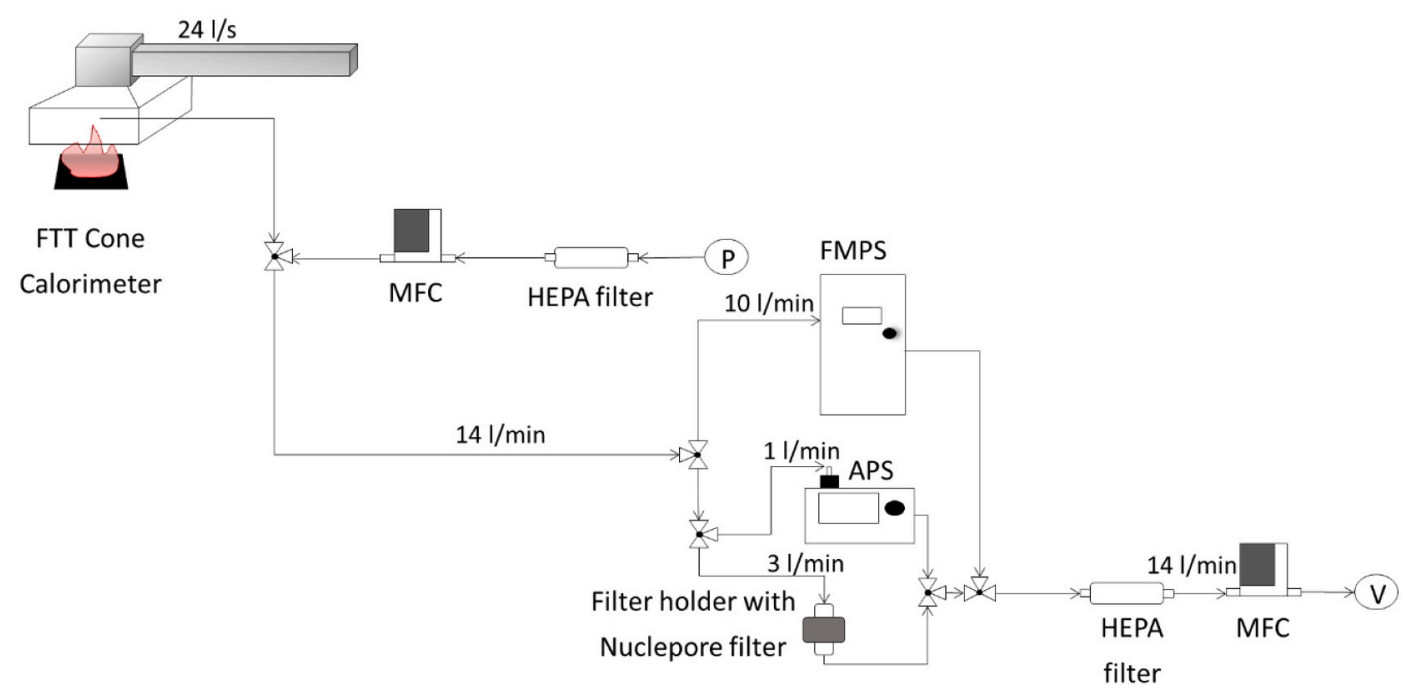

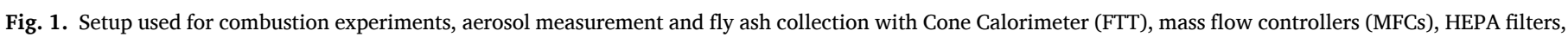

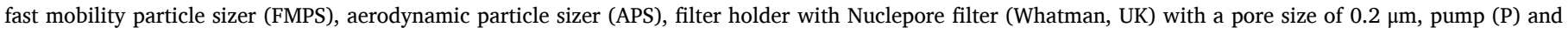
vacuum pump (V). 
three spots on the SEM images.

\subsection{Quantitative determination of the chemical composition of the fly ash by ICP-MS}

ICP-MS NexION 2000 (Perkin Elmer) was employed for quantitative analyses of the chemical composition of the fly ash. Fly ash particles on circular filter sections with a diameter of $8 \mathrm{~mm}$ were digested using the microwave MLS 1200M (MLS) and by applying an inverse king's water (mixture of $3 \mathrm{ml}$ of concentrated nitric acid 67\% (VWR) and $1 \mathrm{ml}$ of concentrated hydrochloric acid (VWR)). The digested samples did not show any precipitation. As a blank reference, the Nuclepore filter was analyzed in a separate measurement. The detected trace elements were subtracted from the elemental composition of the samples, giving rise to the release concentration of the signature elements of the NMs such as $\mathrm{Cu}, \mathrm{Fe}$ and Si. The lowest limits of detection (LODs) were calculated using the threefold standard deviation of the detected values of the blank solutions. LODs: Cu: $0.276 \mu \mathrm{g} /$ filter, Si: $0.078 \mu \mathrm{g} /$ filter, Fe: 0.014 $\mu \mathrm{g} /$ filter, equaling to $\mathrm{Cu}: 5.80 \mathrm{ng} / \mathrm{g}$ fly ash from polymers, to Si: $1.12 \mathrm{ng} /$ $\mathrm{g}$ fly ash from white paint with silica, to $\mathrm{Si}: 21.5 \mathrm{ng} / \mathrm{g}$ fly ash from paper with silica, to Fe: $0.21 \mathrm{ng} /$ fly ash from red paint and to Fe: $3.86 \mathrm{ng} / \mathrm{fly}$ ash from paper with iron oxide.

\section{Experimental results}

\subsection{Aerosol number emission factors}

Fig. 2 shows the $n_{e f s}$ of combustion-generated aerosols from paper, polymeric composites, and applied paints. One circle represents the average of a threefold measurement for the same NEP. The $n_{e f s}$ in the FMPS size range show that there were substantial differences among the different incinerated NEPs. The $n_{e f s}$ from incinerated paper ranged from $2.81 \times 10^{12}$ to $3.22 \times 10^{13} \mathrm{\#} / \mathrm{g}$ and were in average greater than the $n_{e f s}$ from polymeric composites with values of $1.88 \times 10^{12}$ to $5.54 \times 10^{12}$ $\# / g$ and applied paints which ranged from $1.56 \times 10^{11}$ to $4.16 \times 10^{12}$ \#/g (supplementary Table S2).

The $n_{\text {efs }}$ for combusted paper, polymeric composite and applied paint in the APS size range were slightly smaller than those in the FMPS range and ranged from $9.61 \times 10^{8}$ to $1.71 \times 10^{10} \mathrm{\#} / \mathrm{g}, 2.27 \times 10^{9}$ to $1.10 \times$ $10^{10} \# / g$ and $5.19 \times 10^{9}$ to $9.75 \times 10^{9} \# / g$, respectively (supplementary Table S2). For some cases (e.g. the Red paint samples), NEPs with NMs showed a higher $\mathrm{n}_{\mathrm{efs}}$ compared to the reference without NMs, whereas in other cases there was no significant difference between the reference material and the NEP.

Higher NM loading in the NEP did not increase the $n_{e f s}$ in the FMPS range or in the APS range. The difference between the $n_{e f s}$ from any two types of NEPs was assessed via $t$-tests. Table S3 shows the compared categories with the resulting $p$-values and the respective significance. A smaller p-value implied a bigger difference between the two different categories of NEPs.

We noted substantial differences of the $n_{\text {efs }}$ of paper, polymer composites and applied paints in the FMPS range (Table S3). The results implied that NEPs could be classified based on the $n_{e f}$ in the FMPS range. The $n_{e f s}$ in the APS range did not show an obvious dependency on the type of the incinerated NEP.

\subsection{Assessment of the released aerosol size distribution}

The sizes of pristine NMs and released aerosols were compared to evaluate if pristine NMs were released in significant amount and to assess if the NMs were transformed. Pristine NMs had a maximum geometric size of $50 \mathrm{~nm}$ (supplementary Fig. S1 and supplementary Table S1) which could be detected in the electrical mobility size range.

Based on Hinds (1999) and DeCarlo et al. (2004), geometric size and electrical mobility size are similar for compact particles having a shape factor $\chi$ close to 1 and unit elementary charge. Except for the $\mathrm{Fe}_{2} \mathrm{O}_{3}$ nano rods, all other employed $\mathrm{NMs}\left(\mathrm{SiO}_{2}, \mathrm{CuPh}\right.$ thalocyanine and $\mathrm{Fe}_{2} \mathrm{O}_{3}$ nano spheres) were compact or slightly elongated (and had a $\chi$ close to 1 ). For fibers, geometric size and electrical mobility size might differ significantly. In case of the short $\mathrm{Fe}_{2} \mathrm{O}_{3}$ nano rods with a geometric size of 8.4 $\pm 1.8 \mathrm{~nm}$ we calculated an electrical mobility diameter $7.01 \pm 1.4 \mathrm{~nm}$ of using eq. 4 and 5 from Bahk et al. (2013). Thus, the difference was actually rather small.

Table 1 shows the comparison of the sizes of the pristine NMs and the modes of the size distributions of the emitted aerosols. ASDs from PA6 and TPU showed a mode at around $30 \mathrm{~nm}$, whereas the size distributions from PLA showed an additional mode at $102 \mathrm{~nm}$. The ASDs did not show modes corresponding to the size of the pristine CuPhthalocyanine NM $(14.6 \pm 4.9 \mathrm{~nm})$. The ASDs from "White paint $6.0 \mathrm{wt} . \% \mathrm{SiO}_{2}$ " and the respective reference sample "Ref. white paint" showed two modes at around $30 \mathrm{~nm}$ and in size the range of $105 \mathrm{~nm}$ to $124 \mathrm{~nm}$. No peak corresponding to the size of the silane-modified silica NM $(12.0 \pm 2.4$ $\mathrm{nm})$ was found. Similarly, there were two or three modes at about 30 $\mathrm{nm}, 55 \mathrm{~nm}$, and in the range of $102 \mathrm{~nm}$ to $137 \mathrm{~nm}$ for red paint samples a) FMPS

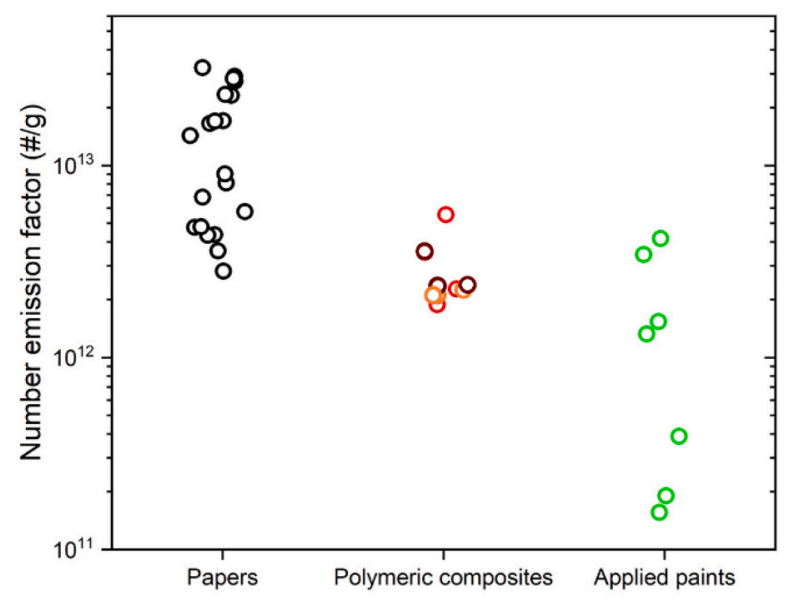

b) APS

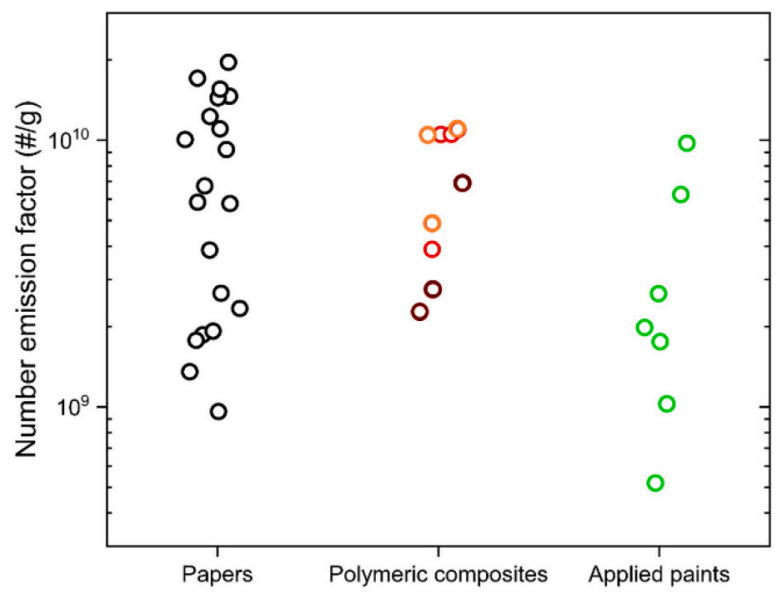

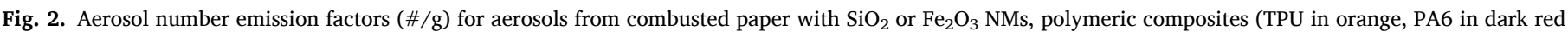

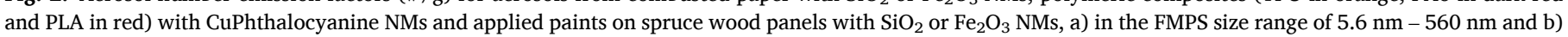

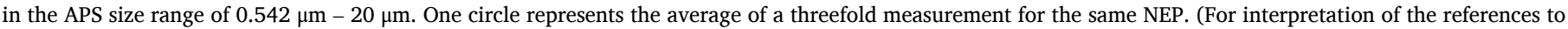
color in this figure legend, the reader is referred to the web version of this article.) 
Table 1

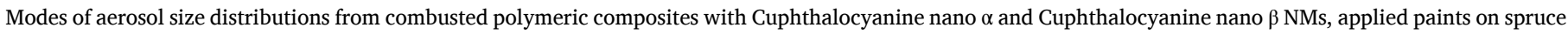
wood panels with $\mathrm{SiO}_{2}$ and $\mathrm{Fe}_{2} \mathrm{O}_{3} \mathrm{NMs}$ and paper with $\mathrm{SiO}_{2}$ and $\mathrm{Fe}_{2} \mathrm{O}_{3} \mathrm{NMs}$ compared to the geometric sizes of the pristine $\mathrm{NMs}$.

\begin{tabular}{|c|c|c|c|c|c|c|c|c|c|c|}
\hline \multirow[b]{2}{*}{ Polymeric composites } & \multirow{2}{*}{$\begin{array}{l}\text { Sample } \\
\text { PA6 }\end{array}$} & \multicolumn{4}{|c|}{$\begin{array}{l}\text { Peak of each mode in FMPS size } \\
\text { range }(n m)\end{array}$} & \multicolumn{4}{|c|}{$\begin{array}{l}\text { Peak of each mode in APS size } \\
\text { range }(\mu \mathrm{m})\end{array}$} & \multirow[t]{2}{*}{ Size of pristine NMs (nm) } \\
\hline & & 28.1 & & & & 0.62 & 0.89 & 2.04 & & \\
\hline & PA6 $\alpha$ & 26.5 & & & & & & 2.00 & & $14.6 \pm 4.9$ \\
\hline & PA6 $\beta$ & 25.8 & & & & 0.58 & 0.87 & 2.21 & & $14.6 \pm 4.9$ \\
\hline & PLA & 27.5 & & & & 0.9 & & & & \\
\hline & PLA $\alpha$ & 34.1 & 101.9 & & & 0.58 & 0.855 & 2.20 & & $14.6 \pm 4.9$ \\
\hline & PLA $\beta$ & 26.2 & 105.6 & & & 0.59 & 0.86 & 2.23 & & $14.6 \pm 4.9$ \\
\hline & TPU & 34.3 & 102.1 & & & 0.58 & 0.89 & 2.10 & & \\
\hline & TPU $\alpha$ & 26.5 & & & & 0.6 & & & & \\
\hline & TPU $\beta$ & 27.3 & & & & 0.58 & 0.86 & 2.02 & & $14.6 \pm 4.9$ \\
\hline \multirow[t]{7}{*}{ Paints (applied on wood panels) } & Ref. white paint & 29.6 & & 105.1 & & 0.56 & 0.81 & 2.31 & & \\
\hline & White paint 6.0 wt. $\% \mathrm{SiO}_{2}$ & 25.6 & & 123.8 & & 0.54 & 0.89 & 2.07 & & $12.05 \pm 2.4$ \\
\hline & Ref. for red paint & 34.2 & & 110.0 & & 0.57 & 0.85 & 2.04 & & \\
\hline & Red paint 7.0 wt. $\% \mathrm{Fe}_{2} \mathrm{O}_{3}$ nano rods & 29.8 & 101.9 & 118.7 & & 0.55 & 0.85 & 2.10 & & $8.4 \pm 1.8$ \\
\hline & Red paint 7.0 wt. $\% \mathrm{Fe}_{2} \mathrm{O}_{3}$ nano spheres & 27.8 & 61.4 & & & 0.54 & 0.86 & 2.08 & & $36.7 \pm 12.4$ \\
\hline & Red paint $1.0 \mathrm{wt} \% \mathrm{Fe}_{2} \mathrm{O}_{3}$ nano rods & 33.9 & 52.9 & 137.6 & & 0.59 & 0.87 & 2.88 & & $8.4 \pm 1.8$ \\
\hline & Red paint 1.0 wt. $\% \mathrm{Fe}_{2} \mathrm{O}_{3}$ nano spheres & 35.3 & 55.1 & 123.5 & & 0.58 & 0.84 & 2.03 & & $36.7 \pm 12.4$ \\
\hline \multirow[t]{16}{*}{ Paper } & Ref., no NM & 16.2 & 19.7 & 34.9 & 96.7 & & & 1.69 & & \\
\hline & Ref., $\mathrm{SiO}_{2} \mathrm{NM}$ & & 19.3 & 40.0 & 99.7 & & & 1.69 & & \\
\hline & $\mathrm{Fe}_{2} \mathrm{O}_{3}$ nano sphere, 0.05 & & 22.4 & & 96.8 & & & & 2.18 & $36.7 \pm 12.4$ \\
\hline & $\mathrm{Fe}_{2} \mathrm{O}_{3}$ nano sphere, 0.5 & & 22.12 & & 102.8 & & & 1.63 & & $36.7 \pm 12.4$ \\
\hline & $\mathrm{Fe}_{2} \mathrm{O}_{3}$ nano sphere, 5 & 18.1 & 21.8 & & 99.2 & & & & 2.02 & $36.7 \pm 12.4$ \\
\hline & $\mathrm{Fe}_{2} \mathrm{O}_{3}$ nano rods, 0.05 & 16.2 & 21.9 & & 98.7 & 0.64 & 0.92 & 1.23 & & $8.4 \pm 1.8$ \\
\hline & $\mathrm{Fe}_{2} \mathrm{O}_{3}$ nano rods, 0.5 & 17.1 & 22.8 & 30.1 & & & 1.07 & 1.69 & 1.86 & $8.4 \pm 1.8$ \\
\hline & $\mathrm{Fe}_{2} \mathrm{O}_{3}$ nano rods, 5 & 17.6 & 25.8 & 34.4 & 97.6 & 0.69 & 0.89 & 1.46 & 1.86 & $8.4 \pm 1.8$ \\
\hline & Commercial paper & & & & & & & & 2.22 & \\
\hline & Ref. no $\mathrm{SiO}_{2}$ & 19.3 & 22.4 & 34.2 & & & & 1.92 & 2.28 & \\
\hline & $\mathrm{SiO}_{2}$ std., $0.8(0.096 \mathrm{~kg} / \mathrm{t}$, active silica $)$ & 18.2 & & 32.0 & 108. & & 0.84 & & & $14.0 \pm 6.6$ \\
\hline & $\mathrm{SiO}_{2}$ std., $3.0(0.36 \mathrm{~kg} / \mathrm{t}$, active silica $)$ & 19.1 & & 36.6 & & & 1.59 & 1.63 & & $14.0 \pm 6.6$ \\
\hline & $\mathrm{SiO}_{2}$ std., 40 (4.8 kg/t, active silica) & 18.1 & 25.0 & 30.7 & 96.8 & & & & 2.12 & $14.0 \pm 6.6$ \\
\hline & $\mathrm{SiO}_{2} \mathrm{Al}, 1.5(0.105 \mathrm{~kg} / \mathrm{t}$, active silica $)$ & 19.0 & 23.0 & 34.7 & 44.4 & & 0.85 & 1.66 & & $14.0 \pm 6.6$ \\
\hline & $\mathrm{SiO}_{2} \mathrm{Al}, 3.0(0.21 \mathrm{~kg} / \mathrm{t}$, active silica $)$ & 16.4 & 19.9 & 38.6 & & & & 1.72 & & $14.0 \pm 6.6$ \\
\hline & $\mathrm{SiO}_{2} \mathrm{Al}, 40(2.8 \mathrm{~kg} / \mathrm{t}$, active silica $)$ & 14.4 & 18.5 & 32.6 & 40.7 & & & 1.92 & 2.28 & $14.0 \pm 6.6$ \\
\hline
\end{tabular}

with $\mathrm{Fe}_{2} \mathrm{O}_{3}$ NMs. The ASDs did not show peaks at the electrical mobility diameter of $7.01 \pm 1.4 \mathrm{~nm}$ that would indicate the presence of $\mathrm{Fe}_{2} \mathrm{O}_{3}$ nano rods. Freestanding $\mathrm{Fe}_{2} \mathrm{O}_{3}$ nano spheres with a diameter of $36.7 \pm$ $12.4 \mathrm{~nm}$ might be part of the respective size distributions since there were modes at $30 \mathrm{~nm}$ and $55 \mathrm{~nm}$. However, the size distributions of the reference sample also showed modes with these diameters. Released aerosols from paper with silica, showed 2 to 4 modes in the range of 14 $\mathrm{nm}$ to about $103 \mathrm{~nm}$. Although there was a mode at $18 \mathrm{~nm}$, the occurrence of this peak could not be linked to the emission of pristine silica particles, which would appear at $14.0 \pm 6.6 \mathrm{~nm}$ (silica std.) or $13.1 \pm$ $2.3 \mathrm{~nm}$ (silica anis $\mathrm{Al}$ ), since the mode at $18 \mathrm{~nm}$ appeared also in the size distribution of the reference papers without silica. Nevertheless, this peak was slightly higher when there were silica particles in the paper. ASDs from paper with $\mathrm{Fe}_{2} \mathrm{O}_{3} \mathrm{NMs}$ showed 2 to 4 modes in the size range of $18 \mathrm{~nm}$ to $110 \mathrm{~nm}$ independent from the type of embedded NMs. All ASDs in the APS size range $0.542 \mu \mathrm{m}$ to $20 \mu \mathrm{m}$ showed modes at aerodynamic diameters of about $0.58 \mu \mathrm{m}, 0.86 \mu \mathrm{m}$ and $2.21 \mu \mathrm{m}$ indicating single pieces of matrix fragments with big diameters or aggregates and agglomerates of particles with smaller diameters.

\subsection{Morphology assessment of aerosol particles}

More than 200 SEM pictures were investigated to evaluate effects induced by the embedded NM, the matrix or the supporting structure (wood in case of applied paints) on the morphology of the fly ash particles. The SEM pictures showed particles with modified (irregular) shapes compared to the embedded NMs and their agglomerates (Fig. 3).

The number of particles on the filter depended on the mass of the burnt sample and the investigated location of the filters. Based on Fig. 3 we could not observe any noticeable effect by the type of embedded NMs nor the NM loading on the morphology of the released aerosols. If NM loadings would be higher than the range tested in this study (max. $7 \mathrm{wt}$
\%), the NM loading could affect the morphology of the fly ash.

\subsection{Chemical characterization of the combustion-generated particles}

\subsubsection{Residual ash}

The chemical composition of the residual ash was assessed via EDXSEM (supplementary Tables S4-S6). The analyses showed high concentrations of chemical elements of the pristine NMs and other fillers of the NEPs. Residual ash from paper contained calcium, carbon and oxygen, which could be related to $\mathrm{CaCO}_{3}$ fillers. Moreover, the detected silicon in the residual ash correlated with the silica loading in the NEP (supplementary Table S4) and the detected aluminum could be attributed to the polyaluminiumchloride component of the product formulation of the papers (see supplementary information). $\mathrm{Fe}$ from $\mathrm{Fe}_{2} \mathrm{O}_{3}$ in paper and $\mathrm{Cu}$ from CuPthalocyanine in polymeric composites could not be detected via EDX-SEM. Potentially $\mathrm{Cu}$ and Fe concentrations in the residual ash were below the detection limits of $0.02 \% \mathrm{Cu}$ and $0.03 \% \mathrm{Fe}$ of the EDX. Another reason could be that NMs deeply embedded in the matrix of the residual ash could potentially not be detected, since the X-rays from EDX analysis could not penetrate deep into the residual ash. The residual ash of the applied paints contained mainly elements from the embedded $\mathrm{SiO}_{2}, \mathrm{TiO}_{2} \mathrm{NMs}$ in case of the white paint and $\mathrm{Fe}_{2} \mathrm{O}_{3} \mathrm{NMs}$ in case of the red paint. Detected $\mathrm{Si}$ and $\mathrm{Fe}$ concentrations correlated with the NM loadings. The residual ash from "Paint with 7.0 wt. $\% \mathrm{Fe}_{2} \mathrm{O}_{3}$ rods" showed a Fe-concentration of $20.7 \%$ whereas the residual ash from "Paint with 1.0 wt.\% $\mathrm{Fe}_{2} \mathrm{O}_{3}$ rods" showed a Fe-concentration of $2.4 \%$. This can be explained by a potential loss of carbon materials and the accumulation of non-volatile elements.

Since the supporting wood panel comprised the majority of the mass of the paint NEPs, the residual elements coming from the wood also need to be considered. The low concentrations of $\mathrm{Al}$ and $\mathrm{S}$ could be attributed to the product formulation of the paint matrix. $\mathrm{K}, \mathrm{Ca}, \mathrm{Mg}, \mathrm{Na}$ and 

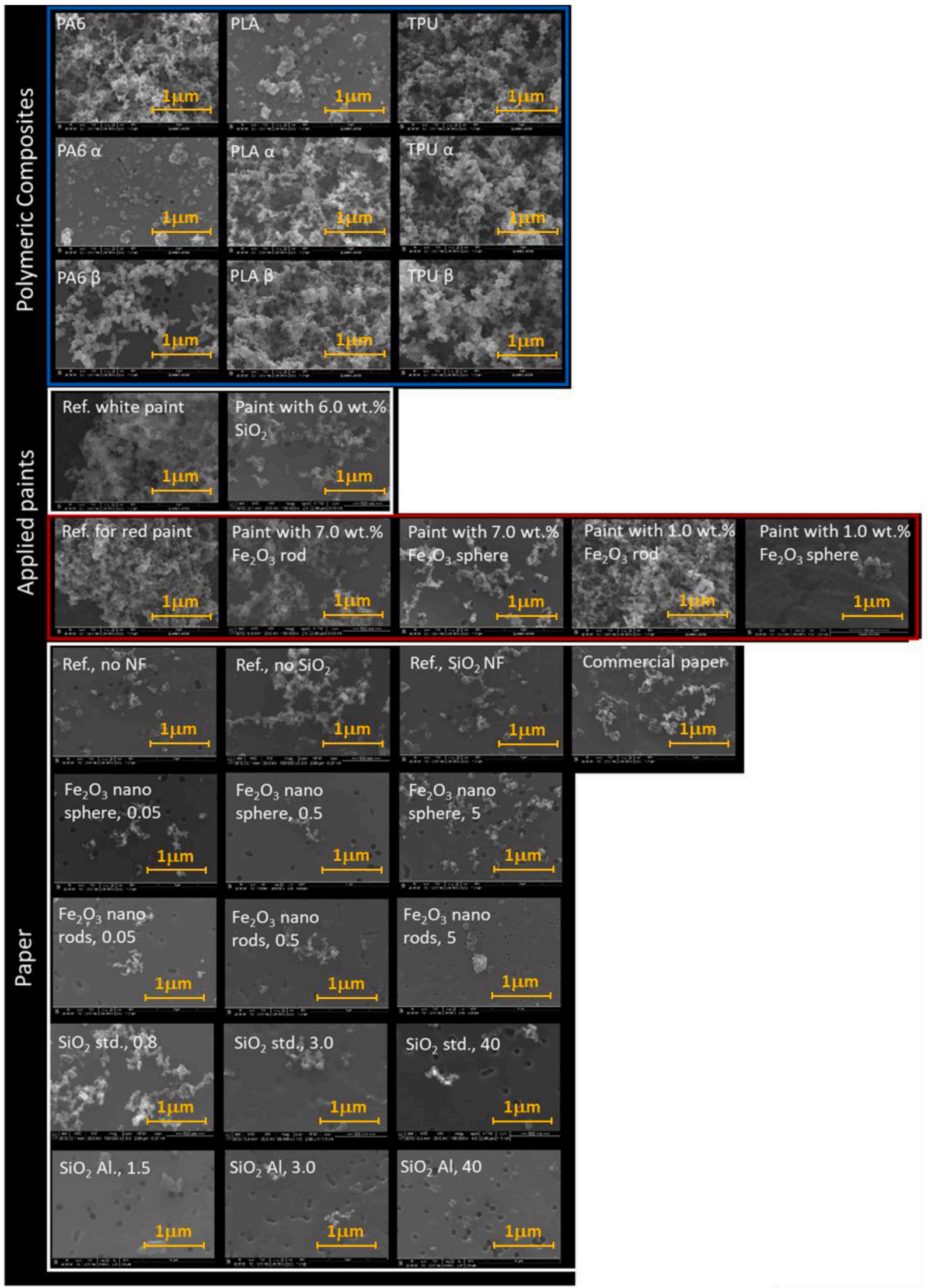

$\mathrm{Fe}_{2} \mathrm{O}_{3}$ nano

sphere, 0.05

$\mathrm{Fe}_{2} \mathrm{O}_{3}$ nano

rods, 0.05

SiO

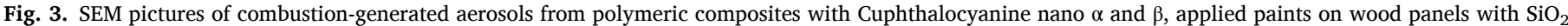
and $\mathrm{Fe}_{2} \mathrm{O}_{3}$ and paper with $\mathrm{SiO}_{2}$ and $\mathrm{Fe}_{2} \mathrm{O}_{3}$. 
partially also Si could be related to the so-called nutrients of the supporting spruce wood panels (Dünisch and Bauch, 1994).

\subsubsection{Released aerosols}

Supplementary Table S7 depicts the results of the qualitative evaluation of the chemical composition of the fly ash via EDX-SEM. Accordingly, these particles consisted mainly of chemical elements of the matrix (carbon, nitrogen, oxygen), oxygen from the air and in some cases marginal fractions of chemical elements ( $\mathrm{Cu}$ and $\mathrm{Si}$ ) which could be attributed to the NMs that were embedded in the NEPs. Fe from $\mathrm{Fe}_{2} \mathrm{O}_{3}$ and $\mathrm{Si}$ from $\mathrm{SiO}_{2}$ could not be detected in the fly ash from the applied paints and paper with $\mathrm{SiO}_{2}$ std. In contrast, low Si-concentrations correlating to the $\mathrm{SiO}_{2}$ loadings in the paper could be detected in the fly ash from paper with embedded aluminum modified $\mathrm{SiO}_{2}$. The detected platinum could be attributed to the platinum coating of the samples for SEM analyses. Details may be referred to supplementary Table S7.

Quantitative determination of the released signature elements of the embedded NMs was achieved via ICP-MS. Fig. 4 depicts the results. The release was calculated relative to the total mass of the fly ash deposited on the filter.

Fly ash from polymeric composites with CuPhthalocyanine NMs show Cu-concentrations in the range of $440 \mu \mathrm{g} / \mathrm{g}$ (PA6 $\beta$ ) to 20,087 $\mu \mathrm{g} / \mathrm{g}$ (PLA $\beta$ ). The crystalline phase of CuPhthalocyanine ( $\alpha$ or $\beta$ ) NM did not strongly affect the $\mathrm{Cu}$ - concentration. In case of PLA and TPU, $\mathrm{Cu}$ from CuPhthalocyanine $\beta$ was released in a higher amount. However, in case of PA6, the Cu-concentration from CuPhthalocyanine $\alpha$ was higher. PLA $\alpha$ released a lower Cu-concentration of $12,569 \mu \mathrm{g} / \mathrm{g}$ than PLA $\beta$, which had a value of $20,087 \mu \mathrm{g} / \mathrm{g}$. PA6 $\alpha$, PA6 $\beta$, TPU $\alpha$ and TPU $\beta$ released $\mathrm{Cu}-$ concentrations of $6820 \mu \mathrm{g} / \mathrm{g}, 440 \mu \mathrm{g} / \mathrm{g}, 658 \mu \mathrm{g} / \mathrm{g}$ and $4704 \mu \mathrm{g} / \mathrm{g}$, respectively.

Fly ash from "White paint $6 \% \mathrm{SiO}_{2}$ " did not show Si element. Fe was only detected for "Red paint $7.0 \% \mathrm{Fe}_{2} \mathrm{O}_{3}$ rods" with a Fe-concentration of $2884 \mu \mathrm{g} / \mathrm{g}$. The fly ash from the $\mathrm{SiO}_{2}$-enhanced paper samples and the commercial paper did not show $\mathrm{Si}$. Fly ash from paper with $\mathrm{Fe}_{2} \mathrm{O}_{3} \mathrm{NMs}$ showed Fe-concentration of $936 \mu \mathrm{g} / \mathrm{g}$ in case of " $\mathrm{Fe}_{2} \mathrm{O}_{3}$ nano rods, 0.5". On the other hand, we did not detect $\mathrm{Fe}$ in the fly ash from the sample with the highest concentration of $\mathrm{Fe}_{2} \mathrm{O}_{3}$ nano rods (" $\mathrm{Fe}_{2} \mathrm{O}_{3}$ nano rods, 5 ”). Uncertainties in sampling and sample pretreatment might have influenced the detected concentrations of the $\mathrm{Fe}, \mathrm{Si}$ and $\mathrm{Cu}$ signature elements.

\section{Discussion}

Combustion of NEPs or waste with intentionally added NMs generates nanoparticles that are released either in form of fly ash or remain as a residue in form of solid ash (Part et al., 2018; Vejerano et al., 2014). According to Vejerano et al. (2014) and Part et al. (2018), the elements of the pristine NMs were sintered with other ash residues and accumulated in the residual ash after combustion. Only small fractions of the pristine NMs were released into the fly ash. According to Mueller et al. (2012), Mueller et al. (2013) and Part et al. (2018), the melting or boiling process of a NM and the bonding strength of the NM to the matrix defined its behavior during combustion. Based on their results, the probability for a NM to remain in the residual ash was higher when the NM was embedded in the matrix than if it was loosely attached to the

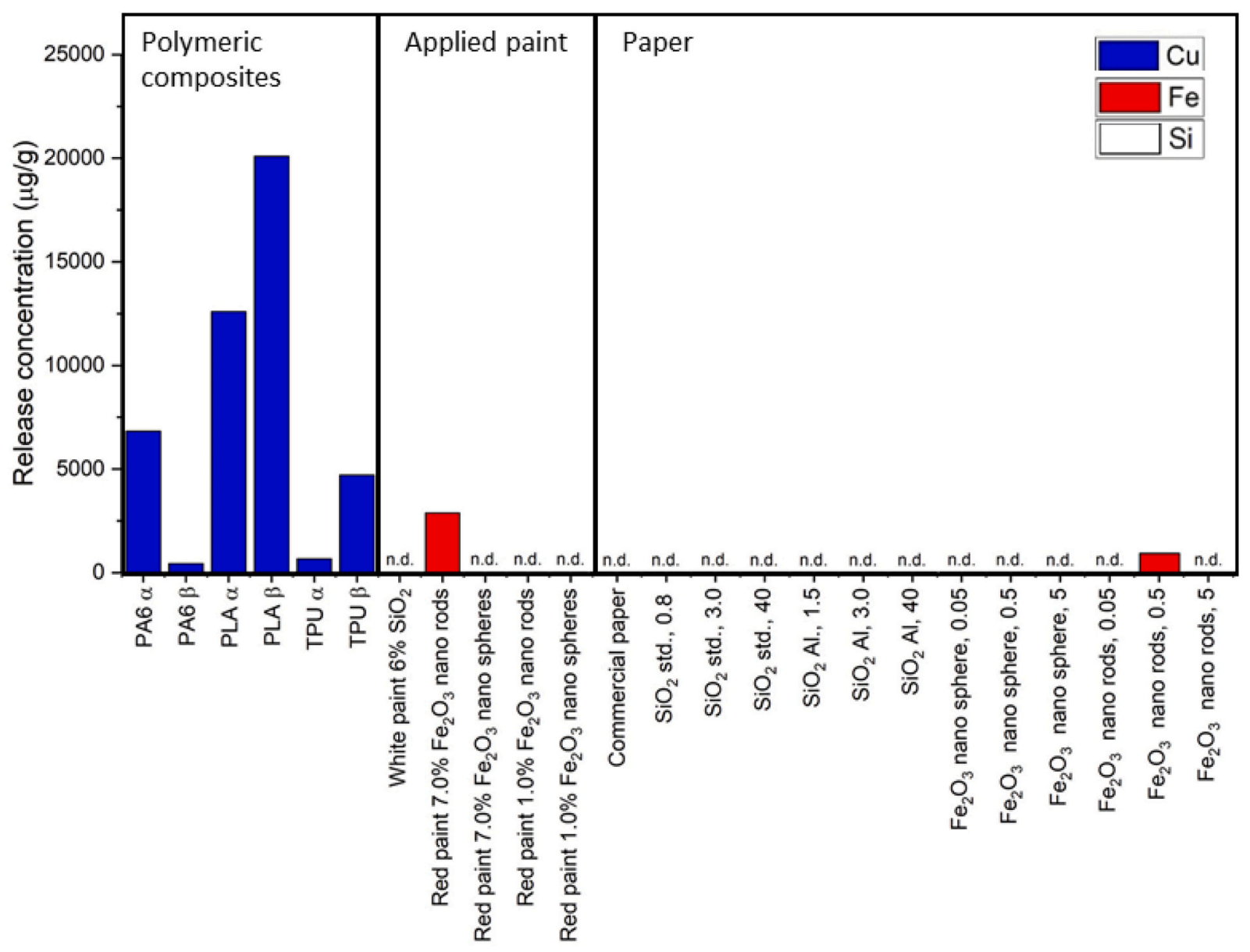

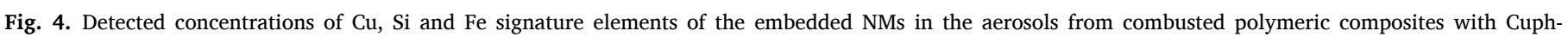

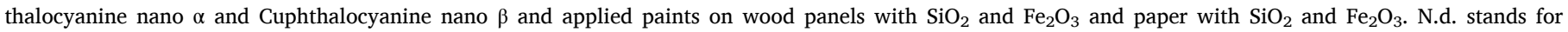
not detected. 
surface of the matrix.

In this study, we explored the release of incidental NMs from NEPs with embedded NMs. We compared experimental data from the combustion-generated particles of multiple NEPs to evaluate the NM release potential and to assess how pristine NM and matrix influence size, shape and chemical composition of the fly ash. Several important findings need to be highlighted. According to our results, the generated nanoparticles in the fly ash came mainly from the matrix of the NEP and just a small fraction, mostly found in the residual ash, from the added NM. The release rates (referring to all types of nanoparticles generated and not only the fraction of added NMs) were dominated by the type of NEP/ matrix and not by the type and loading of the added NM (for a maximum loading of $7.0 \mathrm{wt} \%$ ).

In addition, the phys.-chem. characteristics of the fly ash were influenced by the properties of the pristine NM. Whereas size and morphology of the pristine NMs did not affect the characteristics of the fly ash, there are indications that the melting temperature of the NM had stronger influences. In case the melting point of the NM was above the combustion temperature, we expected NMs accumulating in the residual ash and did not exclude the presence of pristine NMs in the fly ash. However, even at combustion temperatures that are lower than the melting points, the generated heat could induce modification of the pristine NMs, which then could lose their integrity. As described by Part et al. (2018) the vaporized material including generated elements and fragments might recombine / re-condense in the flue gas, which then would affect the shape or chemical composition of the newly generated nanoparticles. We expect that $\mathrm{SiO}_{2}$ and $\mathrm{Fe}_{2} \mathrm{O}_{3} \mathrm{NMs}$ were not melted, since they have melting points of $1600{ }^{\circ} \mathrm{C}$ (Chemical Abstracts Service (CAS) no. 7631-86-9) and $1565{ }^{\circ} \mathrm{C}$ (CAS no. 1309-37-1), respectively, which indicates that they remained in the residual ash. At elevated temperatures (already below $500{ }^{\circ} \mathrm{C}$ ), colloidal silica particles start to sinter to a very low surface area (outside the nano range). All particles would be fully sintered at a temperature of about $900^{\circ} \mathrm{C}$. In addition, the size of the elongated (anisotropic) silica structures was changed during the sintering process.

The efficacy of the sintering process increases due to the presence of Na counter ions. Since Silica anis std. and Silica anis Al had a high content of Na. Due to their high surface area, they sintered even more compared to other amorphous silicas. Moreover, due to the sintering, the anisotropic structure and the size of the particles was very different after the combustion.

In contrast the CuPhthalocyanine NMs could be totally destroyed during the combustion, due to their melting point of $150{ }^{\circ} \mathrm{C}$ (CAS no. 147-14-8).

We detected aerosol release in the nano size range for all NEPs combusted. The total released aerosol concentrations from polymeric composites, paints and paper were quite different.

To assess these differences, we compared the $n_{e f s}$ for the different NEPs. The $n_{e f s}$ for aerosols in the FMPS size range revealed substantial differences among different NEPs (Table S2 and Table S3). Differences in this size range were expected since the release of nanosized particles during the combustion depends strongly on the type of NEP that was combusted. The $n_{\text {efs }}$ of combusted paper ranging from $2.81 \times 10^{12}$ to $3.22 \times 10^{13} \# / g$ were on average greater than the $n_{e f s}$ of polymeric composites $\left(1.88 \times 10^{12}\right.$ to $\left.5.54 \times 10^{12} \# / g\right)$ and much greater than the $n_{\text {efs }}$ of applied paints $\left(1.56 \times 10^{11}\right.$ to $\left.4.16 \times 10^{12} \mathrm{\#} / \mathrm{g}\right)$. The difference in the $n_{\text {efs }}$ in the FMPS range implied that the type of NEP/ matrix (paper, polymer composite or paint on wood panels) could be the determining factor for the aerosol concentration. The difference among the $n_{\text {efs }}$ in the APS size range was not significant for the different types of NEPs (Table S2 and Table S3). The results from the $t$-tests on $n_{\text {efs }}$ in the FMPS range implied that different NEPs could be categorized based on the $n_{e f}$ in the FMPS range, which corresponded to the potential of the NEP to release aerosols during combustion. Thus, we defined three categories polymeric composites, applied paints and paper. Referring to Table S2, we conclude that there was no correlation between the NM loading of the
NEPs and the aerosol number emission factor.

However, there are limitations of the FMPS instrument that need to be taken into account. Several studies reported that particles in unipolar diffusion chargers were wrongly sized in the upper working size ranges (Price et al., 2014; Fonseca et al., 2016; Levin et al., 2015; Zimmerman et al., 2015). Based on Price et al. (2014), FMPS measurements detected to some extent lower concentrations at an electrical mobility diameter of $110 \mathrm{~nm}$ compared to the scanning mobility particle sizer that showed a higher accuracy compared to FMPS. The lower accuracy of the FMPS might have affected the detected aerosol concentration.

Since the matrix comprised the major part of the NEP used in this study, the type of matrix drove the amount of generated nanoparticles whereas the embedded amount of NMs did not strongly influence the amount of generated nanoparticles. We suppose that if the NM loading in the NEP would be significantly higher, it could affect the concentration of generated aerosols. For the case of pigments, the tested NEPs are intensely colored (Table S1), confirming that the tested concentrations of NM cover the industrially relevant range for pigments.

Since total aerosol concentrations from samples with NMs were not remarkably different compared to those from reference samples without NMs, we could not conclude a specific influence of adding NMs to composite matrices on the total aerosol concentrations. This goes along with the findings of Vejerano et al. (2014) who found that the particle emission factor of surrogate waste from polymers was not significantly increased due to the presence of NMs.

To assess the generation of new particles during the combustion and to evaluate the release of pristine NMs we compared the geometric sizes of the pristine NMs with the modes of the released ASDs. The ASDs from paints and polymers showed a dominant mode at about $30 \mathrm{~nm}$ and a minor mode at about $100 \mathrm{~nm}$ whereas the ASDs from paper showed small modes at about $17 \mathrm{~nm}$ and $20 \mathrm{~nm}$, which sometimes replaced the mode at $30 \mathrm{~nm}$. The sizes of the detected modes in the aerosol did not correspond to the sizes of the pristine NMs that were embedded in the NEPs. If CuPhthalocyanine, $\mathrm{SiO}_{2}$ or $\mathrm{Fe}_{2} \mathrm{O}_{3}$ were released in significant amount in pristine form, there would be modes with the sizes of the pristine NMs.

Nonetheless, this does not mean that the embedded NMs were not released, because if they were released in very little amount, the size of the pristine NM could not be seen on the ASDs.

The ASDs from all NEPs showed multiple modes in the APS range, indicating big particles (e.g. matrix fragments) or agglomerates of smaller particles. The underlying self-aggregation mechanism for combustion-generated aerosols was described by Forster et al. (2016). Many particles in the fly ash showed different morphologies from pristine NMs and had an irregular shape. However, we could not conclude that all particles had a different morphology from the pristine NMs since some particles might be hidden behind other particles in the SEM images.

The morphology changes of the released particles compared to the pristine manufactured NMs might affect the toxic effects of the released particles. However, the final toxic effects need be evaluated considering the amount / fraction of released NMs that were embedded in the NEPs.

The EDX-SEM analysis of the fly ash showed mainly chemical elements of the matrices used.

In the case of paper, EDX-SEM analysis showed high amount of $\mathrm{CaCO}_{3}$ (Table S4) which was apart from the small content of silica and $\mathrm{Fe}_{2} \mathrm{O}_{3}$ a major part of the product formulation of the paper (Table S1). In some cases, marginal amounts of chemical elements were found that could be related to the pristine NMs. This correlates with the results from Vejerano et al. (2014) and Vejerano et al. (2013), who investigated the combustion of plastic and paper wastes that contained different kinds of $\mathrm{NMs}\left(\mathrm{TiO}_{2}, \mathrm{CeO}_{2}, \mathrm{Ag}, \mathrm{Fe}_{2} \mathrm{O}_{3}\right.$, etc.) using a combustion temperature of $850{ }^{\circ} \mathrm{C}$. Their results implied that the majority of NMs remained in the residual ash whereas only a small amount of the pristine NMs was released in form of fly ash.

ICP-MS determination of the released concentrations of $\mathrm{Cu}, \mathrm{Si}, \mathrm{Fe}$ 
signature elements of the NMs in the fly ash showed substantial differences. PLA released more copper than PA6 and TPU among the polymeric composites. Thus, the type of matrix affected the $\mathrm{Cu}-$ concentration in the fly ash. In addition, the behavior of the NM influenced the concentration of the released signature elements. The copper concentration in the fly ash from polymeric composites was in comparison much higher than the concentrations of $\mathrm{Si}$ and $\mathrm{Fe}$ in paint and paper samples that contained $\mathrm{SiO}_{2}$ and $\mathrm{Fe}_{2} \mathrm{O}_{3}$.

A reason could be that the $\mathrm{SiO}_{2}$ and $\mathrm{Fe}_{2} \mathrm{O}_{3} \mathrm{NM}$ were not melted due to their melting points of $1600^{\circ} \mathrm{C}$ and $1565^{\circ} \mathrm{C}$, which thereby reduced the concentration of the signature elements in the fly ash. Another reason, why no significant release of Si could be detected in the fly ash could be the sintering of the colloidal silica particles, which increased the probability of the Si to remain in the residual ash and thereby reduced the probability of $\mathrm{Si}$ in the fly ash. In contrast, the pristine CuPhthalocyanine NMs were melted due to their melting point of $150{ }^{\circ} \mathrm{C}$ and released in higher amounts.

In case of paint and paper, little amount of Fe was detected in the fly ash from the red paint with $7.0 \mathrm{wt} \% \mathrm{Fe}_{2} \mathrm{O}_{3}$ nano rods and from the paper with $0.05 \% \mathrm{Fe}_{2} \mathrm{O}_{3}$ nano rods. With a length of $8.4 \pm 1.8 \mathrm{~nm}$, rod-shaped $\mathrm{Fe}_{2} \mathrm{O}_{3} \mathrm{NMs}$ had a smaller geometric size than the spherical NMs that had a diameter of $36.7 \pm 12.4 \mathrm{~nm}$. Iron was only detected for NEPs with rodshaped $\mathrm{Fe}_{2} \mathrm{O}_{3} \mathrm{NMs}$, but not for the NEPs with spherical $\mathrm{Fe}_{2} \mathrm{O}_{3}$ NMs. This implied that shape and size of the $\mathrm{Fe}_{2} \mathrm{O}_{3}$ NM affected the Feconcentration in the fly ash particles. However, the data were too limited for a definite conclusion. The detected Si-values in the fly ash from the paper and paint samples with silica were similar to the blank values of the Nuclepore filter. Thus, the Si amount was not significant. Sampling or pretreatment issues or very low concentrations of Fe and $\mathrm{Si}$ that were below the detection limits and differences of the LODs, which depended on the sample mass, could have affected the results and might limit the evaluation of the concentrations of the Fe and Si signature elements in the fly ash.

Similarly, Singh et al. (2019) who investigated incineration-induced $\mathrm{NM}$ release for acryl-based polymer composites with $\mathrm{SiO}_{2}, \mathrm{Fe}_{2} \mathrm{O}_{3}$ and $\mathrm{CuO} \mathrm{NMs}$ in various loading from 0.3 to $20 \mathrm{wt} \%$ could not detect $\mathrm{Si}$ in the released aerosol. Only $\mathrm{Fe}$ or $\mathrm{Cu}$ could be detected. Haynes et al. (1982) showed that a small fraction of refractory oxides $(\mathrm{CaO}, \mathrm{MgO}$, $\mathrm{SiO}_{2}, \mathrm{Fe}_{2} \mathrm{O}_{3}$ ) was reduced to volatile sub oxides or elements, which diffused away from the burning particle. Since the temperature used for the combustion $\left(570{ }^{\circ} \mathrm{C}\right)$ was lower than $1750{ }^{\circ} \mathrm{C}$ above which $\mathrm{SiO}_{2}$ particles would become volatile, volatile $\mathrm{SiO}_{2}$ particles were not expected to occur.

Results from Singh et al. (2019) who applied various NM loadings in the range of 0.3 to $20 \mathrm{wt} \%$, implied that higher NM loadings in the NEPs, could be linked to higher concentrations of the signature elements of the respective NMs in the fly ash. The results from this study did not show such a trend. The reason could be that the NM loadings in the commercial NEPs that were used in this study were smaller.

Given the low concentrations of signature elements of the manufactured NMs in released in the fly ash and the morphology changes indicating a bigger size of released particles in comparison to the pristine, manufactured NMs and particle agglomerates there are observations indicating different toxic effects of the released fly ash particles compared to the pristine NMs.

The EDX analysis of the residual ash from the samples that were burnt in this study showed high concentrations of chemical elements of the embedded NMs, which implied that high fractions of the NMs, which were embedded in the NEP, remained in the residual ash.

\section{Conclusion}

We assessed the influence of the type of matrix and the type of pristine NM on the concentration and the chemical composition of combustion-generated aerosols from commercial NEPs such as paint, polymeric composites and paper with $\mathrm{SiO}_{2}, \mathrm{Fe}_{2} \mathrm{O}_{3}$ and
CuPhthalocyanine NMs. To simulate particle release during accidental burning under outdoor conditions, the combustion conditions were intentionally different from the legally required conditions of waste incineration. Physical-chemical characterization of the fly ash showed particles with modified chemical composition and transformed size as compared to the pristine NMs. The fly ash particles gained their chemical composition mainly from the matrix and only to a minor fraction from type the pristine NMs.

Considering aerosol concentrations, $n_{e f s}$, concentrations of released signature elements and morphologies of the released particles, we conclude that the physical-chemical characteristics of the combustiongenerated fly ash from the NEPs, that were used in this study, were simultaneously influenced by the matrix type, the properties of the pristine NM and the process (combustion) (Fig. 5). The calculated $n_{\text {efs }}$ in the FMPS range depended on the type of NEP, which implied that the NEPs could be categorized according to their potential to release aerosols when they were burnt. It turned out that the embedded NMs did not strongly affect this release potential. The generated data facilitates a comprehensive risk assessment of NEPs.

\section{Credit author statement}

This Credit Author Statements outlines all authors' individual contributions:

Tobias Hammer: Conceptualization, Methodology, Investigation, Methodology Validation, Visualization, Data Curation, Writing - Original Draft - Revised Manuscript

Nathan Bossa: Data Curation, Writing - Original Draft

Michael Persson: Data Curation, Writing - Original Draft

Adrian Wichser: Methodology, Investigation

Ken Lehner: Methodology, Investigation

Emmanuel Ruggiero: Writing - Original Draft

Ana Sofia Fonseca: Writing - Original Draft

Milijana Jovic: Methodology, Investigation, Writing - Original Draft

Sabyasachi Gaan: Methodology, Writing - Original Draft

Wendel Wohlleben: Visualization, Writing - Original Draft

Jing Wang: Conceptualization Methodology, Supervision, Project administration, Funding acquisition, Writing - Original Draft - Revised Manuscript

\section{Funding}

This study was financed by the European project GRACIOUS (project number: 760840).

\section{Declaration of Competing Interest}

The authors declare that they have no known competing financial interests or personal relationships that could have appeared to influence
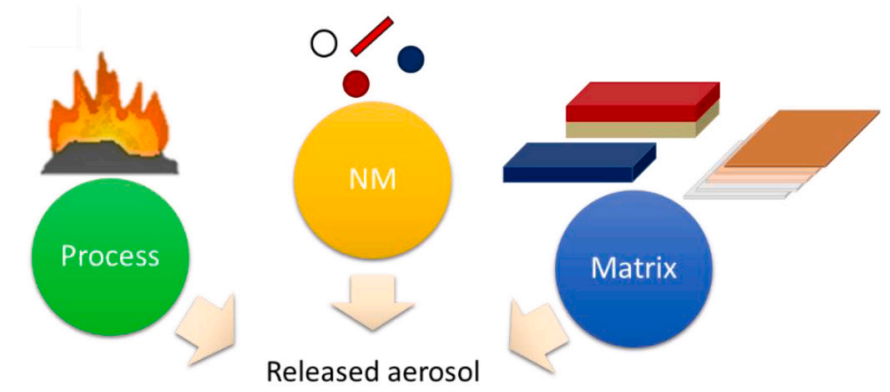

Released aerosol

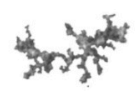

Fig. 5. Graphic showing the influence of process, nanomaterial (NM) and matrix on the released aerosol. 
the work reported in this paper.

\section{Acknowledgement}

The authors thank Dr. Davide Bleiner for his support and for providing the lab equipment for the chemical analyses of the fly ash.

\section{Appendix A. Supplementary data}

Supplementary data to this article can be found online at https://doi. org/10.1016/j.impact.2021.100307.

\section{References}

Bahk, Y.K., Buha, J., Wang, J., 2013. Determination of geometrical length of airborne carbon nanotubes by electron microscopy, model calculation, and filtration method. Aerosol Sci. Technol. 47 (7), 776-784. https://doi.org/10.1080/ 02786826.2013 .791745 .

Basinas, I., Sánchez Jiménez, A., Galea, K.S., van Tongere, M., Hurley, F., 2018. A systematic review of the routes and forms of exposure to engineered nanomaterials. Ann. Work Expo Health 62, 639-662.

Bello, D., Martin, J., Santeufemio, C., Sun, Q., Bunker, K.L., S. M, Demokritou P., 2013 Physicochemical and morphological characterisation of nanoparticles from photocopiers: implications for environmental health. Nanotoxicology 7 (5), 989-1003. https://doi.org/10.3109/17435390.2012.689883.

Brar, S.K., Verma, M., Tyagi, R.D., Surampalli, R.Y., 2010. Engineered nanoparticles in wastewater and wastewater sludge - Evidence and impacts. Waste Manage. Volume 30 (3), 504-520. https://doi.org/10.1016/j.wasman.2009.10.012.

Breuer, O., Sundararaj, U., 2004. Big returns from small fibers: a review of polymer/ carbon nanotube composites. Polym. Compos. 25, 630-645. https://doi.org/ 10.1002/pc. 20058.

Buha, J., Mueller, N., Nowack, B., Ulrich, A., Losert, S., Wang, J., 2014. Physical and chemical characterization of fly ashes from Swiss waste incineration plants and determination of the ash fraction in the nanometer range. Environ. Sci. Technol. 48 (9), 4765-4773. https://doi.org/10.1021/es4047582.

Gonçalves, C., Gonçalves, I.C., Magalhães, F.D., Pinto, A.M., 2018. Poly(Lactic Acid) Composites Containing Carbon-Based Nanomaterials: A Review. MDPI.

Chemical Abstracts Service, 2020. CuPhthalocyanine: CAS no. 147-14-8, SiO2: CAS no. 7631-86-9, Fe2O3 CAS no 1309-37-1. https://www.cas.org/.

Chivas-Joly, C., et al., 2014. Influence of carbon nanotubes on fire behaviour and aerosol emitted during combustion of thermoplastics. Fire Mater. 38 (1), 46-62.

Chivas-Joly, C., Longuet, C., Pourchez, J., Leclerc, L., Sarry, G., Lopez-Cuesta, J.-M., Mar. 2019. Physical, morphological and chemical modification of Al-based nanofillers in by-products of incinerated nanocomposites and related biological outcome. J. Hazard. Mater. 365, 405-412 no. September 2018.

DeCarlo, P.F., Slowik, J.G., Worsnop, D.R., Davidovits, P., Jimenez, J.L., 2004. Particle morphology and density characterization byCombined mobility and aerodynamic diameter measurements. Part 1: theory. Aerosol Science and Technology 38, 1185-1205. https://doi.org/10.1080/027868290903907.

Dünisch, O., Bauch, J., 1994. Influence of mineral elements on wood formation of old growth spruce (Picea abies [L.] Karst.). Holzforschung 48 (s1), 5-14. https://doi.org/ 10.1515/hfsg.1994.48.s1.5.

Fonseca, A.S., Viana, M., Pérez, N., Alastuey, A., Querol, X., Kaminski, H., Todea, A.M. Monz, C., Asbach, C., 2016. Intercomparison of a portable and two stationary mobility particle sizers for nanoscale aerosol measurements. Aerosol Sci. Technol. 50 (7), 653-668. https://doi.org/10.1080/02786826.2016.1174329.

Froggett, S.J., Clancy, S.F., Boverhof, D.R., et al., 2014. A review and perspective of existing research on the release of nanomaterials from solid nanocomposites. Part Fibre Toxicol. 11, 17. https://doi.org/10.1186/1743-8977-11-17.

Hammer, T., Gao, H., Pan, Z., Wang, J., 2020. Relationship between aerosols exposure and lung deposition dose. Aerosol Air Qual. Res. 20, 1083-1093. https://doi.org/ 10.4209/aaqr.2020.01.0033.

Hansen, S.F., Hartmann, N.B., Baun, A., 2015. Transformation and distribution processes governing the fate and behaviour of nanomaterials in the environment: an overview. In: Sustainable Nanotechnology Conference 2015: Conference abstracts Venice, Italy.

Haynes, B.S., Neville, M., Quann, R.J., Sarofim, A.F., 1982. Factors governing the surface enrichment of fly ash in volatile trace species. J. Colloid Interface Sci. 87 (1), 266-278, 0021-9797. https://doi.org/10.1016/0021-9797(82)90388-5.

Hinds, W.C., 1999. Aerosol Technology: Properties, Behavior and Measurement of Airborne Particles. Wiley-Interscience, New York.

Keller, A., Lazareva, A., 2014. Predicted releases of engineered nanomaterials: from global to regional to local environ. Sci. Technol. Lett. 1, 65-70. https://doi.org/ 10.1021/ez400106t.

Kittelson, D.B., Watts, W.F., Johnson, J.P., 2004. Nanoparticle emissions on Minnesota highways. Atmospheric Environment 38 (1), 9-19. https://doi.org/10.1016/j. atmosenv.2003.09.037.

Kotnarowska, D., Przerwa, M., Szumiata, T., 2014. Resistance to erosive wear of epoxypolyurethane coating modified with nanofillers. J. Mater. Sci. Res. 3 (2) https://doi. org/10.5539/jmsr.v3n2p52.
Kuhlbusch, T.A., Fissan, H., Asbach, C., 2010. Measurement and detection of nanoparticles within the environment. Nanotechnology. https://doi.org/10.1002/ 9783527628155 .nanotech017.

Landsiedel, R., 2016. Concern-driven integrated approaches for the grouping, testing andassessment of nanomaterials. Environ. Pollut. 218, 1376-1380.

Le, J.-L., Du, H., Pang, S.D., 2014. Use of 2D graphene nanoplatelets (GNP) in cement composites for structural health evaluation. Compos. Part B 67, 555-563. https:// doi.org/10.1016/j.compositesb.2014.08.005.

Levin, M., Gudmundsson, A., Pagels, J.H., Fierz, M., Mølhave, K., Londahl, J., Jensen, K. A., Koponen, I.K., 2015. Limitations in the use of unipolar charging for electrical mobility sizing instruments: A study of the fast mobility particle sizer. Aerosol Sci. Technol. 49 (8), 556-565. https://doi.org/10.1080/02786826.2015.1052039.

Limited, R.E.-S.P., 2011. Nanotechnology Market Forecast to 2013. RNCOS E-Services Private. Hazard assessment of nanomaterials in consumer products.

Madkour, L.H., 2019. Introduction to nanotechnology (NT) and nanomaterials (NMs). In: Nanoelectronic materials. Advanced structured materials, 116. Springer, Cham. https://doi.org/10.1007/978-3-030-21621-4_1.

Mahrholz, T., Stängle, J., Sinapius, M., 2009. Quantitation of the reinforcement effect of silica nanoparticles in epoxy resins used in liquid composite moulding processes. Compos. A: Appl. Sci. Manuf. 40 (3), 235-243.

Massari, A., Beggio, M., Hreglich, S., Marin, R., Zuin, S., 2014. Behavior of TiO2 nanoparticles during incineration of solid paint waste: A lab-scale test. Waste Manag. 34 (10), 1897-1907. ISSN 0956-053X. https://doi.org/10.1016/j.wasman.2014.0 5.015 .

Ministère de l'Environnement, D.1.É.e.d.1.M., 2015. Éléments issus des déclarations des substances à l'état nanoparticulaire: Exercice, p. 2015.

Mitrano, D.M., Motellier, S., Clavaguera, S., Nowack, B., 2015. Review of nanomaterial aging and transformations through the life cycle of nano-enhanced products. Environ. Int. 77, 132-147. ISSN 0160-4120. https://doi.org/10.1016/j.envint.20 15.01.013.

Mueller, N.C., Nowack, B., Wang, J., Ulrich, A., Buha, J., 2012. Nanomaterials in waste incineration and landfills. In: Internal Empa-Report. Empa-Swiss Federal Laboratories for Materials Science and Technology.

Mueller, N.C., Buha, J., Wang, J., Ulrich, A., Nowack, B., 2013. Modeling the flows of engineered nanomaterials during waste handling. Environ. Sci. Processes Impacts 15, 251-259. https://doi.org/10.1039/C2EM30761H.

Nowack, B., Bucheli, T.D., 2007. Occurrence, behavior and effects of nanoparticles in the environment. Environ. Pollut. 150, 5-22. https://doi.org/10.1016/j. envpol.2007.06.006.

Nowack, B., Ranville, J.F., Diamond, S., Gallego-Urrea, J.A., Metcalfe, C., Rose, J., et al., 2012. Potential scenarios for nanomaterial release and subsequent alteration in the environment. Environ. Toxicol. Chem. 31 (1), 50-59. https://doi.org/10.1002/ etc. 726 .

Oischinger, J., Meiller, M., Daschner, R., Hornung, A., Warnecke, R., 2019. Fate of nano titanium dioxide during combustion of engineered nanomaterial-containing waste in a municipal solid waste incineration plant. Waste Manag. Res. 37 (10), 1033-1042. https://doi.org/10.1177/0734242X19862603.

Oomen, A.G., Bleeker, E.A.J., Bos, P.M.J., Van Broekhuizen, F., Gottardo, S. Groenewold, M., Hristozov, D., Hund-Rinke, K., Irfan, M.-A., Marcomini, A., Peijnenburg, W.J.G.M., Rasmussen, K., Jiménez, A.S., Scott-Fordsmand, J.J., Van Tongeren, M., Wiench, K., Wohlleben, W., Landsiedel, R., 2015. Grouping and readacross approaches for risk assessment of nanomaterials. Int. J. Environ. Res. Public Health 12, 13415-13434.

Part, F., Berge, N., Baran, P., Stringfellow, A., Sun, W., Bartelt-Hunt, S., Mitrano, D., Li, L., Hennebert, P., Quicker, P., C. Bolyard S., Huber-Humer M., 2018. A review of the fate of engineered nanomaterials in municipal solid waste streams. Waste Manage. 75, 427-449. ISSN 0956-053X. https://doi.org/10.1016/j.wasman.2018.0 2.012.

Pope III, C.A., Dockery, D.W., Schwartz, J., 1995. Review of epidemiological evidence of health effects of particulate air pollution. Inhal. Toxicol. 7, 1-18.

Potts, J.R., Dreyer, D.R., Bielawski, C.W., Ruoff, R.S., 2011. Graphene-based polymer nanocomposites. Polymer 52, 5-25. https://doi.org/10.1016/j. polymer.2010.11.042.

Price, H.D., Stahlmecke, B., Arthur, R., Kaminski, H., Lindermann, J., Däuber, E., Asbach, C., Kuhlbusch, T.A.J., BéruBé, K.A., Jones, T.P., 2014. Comparison of instruments for particle number size distribution measurements in air quality monitoring. J. Aerosol Sci. 76, 48-55. https://doi.org/10.1016/j. jaerosci.2014.05.001.

Roes, L., Patel, M.K., Worrell, E., Ludwig, C., 2012. Preliminary evaluation of risks related to waste incineration of polymer nanocomposites. Sci. Total Environ. 417, 76-86.

Rothen-Rutishauser, B.M., Schürch, S., Haenni, B., Kapp, N., Peter, G., 2006. Interaction of fine particles and nanoparticles with red blood cells visualized with advanced microscopic techniques. Environ. Sci. Technol. 40 (14), 4353-4359. https://doi.org/ 10.1021/es0522635.

Ruggiero, E., Vilsmeier, K., Mueller, P., Pulbere, S., Wohlleben, W., 2019. Environmental release from automotive coatings are similar for different (nano)forms of pigments. Environ. Sci. Nano 6 (10), 3039-3048.

Schlagenhauf, L., Kuo, Y., Bahk, Y.K., et al., 2015. Decomposition and particle release of a carbon nanotube/epoxy nanocomposite at elevated temperatures. J. Nanopart. Res. 17, 440. https://doi.org/10.1007/s11051-015-3245-5.

Schulz, H., Harder, V., Ibald-Mulli, A., Khandoga, A., Koenig, W., Krombach, F. Radykewicz, R., Stampfl, A., Thorand, B., Peters, A., 2005. Cardiovascular effects of fine and ultrafine particles. J. Aerosol Med. 18, 1-22.

Seipenbusch, M., Mingzhou, Y., Asbach, C., Kuhlbusch, T.A.J., Lidé, G., 2014. From source to dose: Emission, transport, aerosol dynamics and dose assessment for 
workplace aerosol exposure. In: Vogel, U. (Ed.), Handbook of Nanosafety Measurement, Exposure and Toxicology. Academic Press, Elsevier, Amsterdam, Netherlands, pp. 135-171.

Singh, D., Sotiriou, G.A., Zhang, F., Mead, J., Bello, D., Wohlleben, W., Demokritou, P., 2016. End-of-life thermal decomposition of nano-enabled polymers: effect of nanofiller- loading and polymer matrix on byproducts. Environ. Sci. Nano 3 (6), 1293-1305.

Singh, D., Schifman, L.A., Watson-Wright, C., Sotiriou, G.A., Oyanedel-Craver, V., Wohlleben, W., Demokritou, P., 2017. Nanofiller presence enhances polycyclic aromatic hydrocarbon (PAH) profile on nanoparticles released during thermal decomposition of nano-enabled thermoplastics: potential environmental health implications. Environ. Sci. Technol. 51 (9), 5222-5232. https://doi.org/10.1021/ acs.est.6b06448.

Singh, D., Wohlleben, W., De La Torre Roche, R., White, J.C., Demokritou, P., 2019. Thermal decomposition/incineration of nano-enabled coatings and effects of nanofiller/matrix properties and operational conditions on byproduct release dynamics: potential environmental health implications. NanoImpact 13, 44-55 no. September.

Sotiriou, G.A., Singh, D., Zhang, F., Wohlleben, W., Chalbot, M.-C.G., Kavouras, I.G., Demokritou, P., 2015. An integrated methodology for the assessment of environmental health implications during thermal decomposition of nano-enabled products. Environ. Sci. Nano 2015 (2), 262-272. https://doi.org/10.1039/ C4EN00210E.

Sotiriou, G.A., Singh, D., Zhang, F., Chalbot, M.-C.G., Spielman-Sun, E., Hoering, L., Kavouras, I.G., Lowry, G.V., Wohlleben, W., Demokritou, P., 2016. Thermal decomposition of nano-enabled thermoplastics: possible environmental health and safety implications. J. Hazard. Mater. 305, 87-95. ISSN 0304-3894. https://doi.org/ 10.1016/j.jhazmat.2015.11.001.

Sow, C., Riedl, B., Blanchet, P., 2011. UV-waterborne polyurethane-acrylate nanocomposite coatings containing alumina and silica nanoparticles for wood: mechanical, optical, and thermal properties assessment. J. Coat. Technol. Res. 8 (2), 211-221. https://doi.org/10.1007/s11998-010-9298-6.

Surendhiran, D., Cui, H., Lin, L., 2020. Mode of transfer, toxicity and negative impacts of engineered nanoparticles on environment, human and animal health. In: Hussain, C. M. (Ed.), The ELSI Handbook of Nanotechnology. https://doi.org/10.1002/ 9781119592990.ch9.

Vejerano, E.P., Holder, A.L., Marr, L.C., 2013. Emissions of polycyclic aromatic hydrocarbons, polychlorinated dibenzo-p-dioxins, and dibenzofurans from incineration of nanomaterials. Environ. Sci. Technol. 47 (9), 4866-4874.

Vejerano, E.P., Leon, E.C., Holder, A.L., Marr, L.C., 2014. Characterization of particle emissions and fate of nanomaterials during incineration. Environ. Sci. Nano 1 (2) $133-143$.

Walser, T., Limbach, L., Brogioli, R., et al., 2012. Persistence of engineered nanoparticles in a municipal solid-waste incineration plant. Nat. Nanotech 7, 520-524. https:// doi.org/10.1038/nnano.2012.64.

Wang, J., Schlagenhauf, L., Setyan, A., 2017. Transformation of the released asbestos, carbon fibers and carbon nanotubes from composite materials and the changes of their potential health impacts. J. Nanobiotechnol. 15 (1), 15.

Watson-Wright, C., Singh, D., Demokritou, P., 2017. Toxicological implications of released particulate matter during thermal decomposition of nano-enabled thermoplastics. NanoImpact 5, 29-40.

Wigger, H., Wohlleben, W., Nowack, B., 2018. Redefining environmental nanomaterial flows: consequences of the regulatory nanomaterial definition on the results of environmental exposure models. Environ. Sci. Nano 5, 1372-1385.

Zimmerman, N., Jeong, C.-H., Wang, J.M., Ramos, M., Wallace, J.S., Evans, G.J., 2015. A source-independent empirical correction procedure for the fast mobility and engine exhaust particle sizers. Atmos. Environ. 100, 178-184. https://doi.org/ 10.1016/j.atmosenv. 2014.10.054. 